\title{
Effect of Sodium Ascorbate on Dentin Bonding After Two Bleaching Techniques
}

\author{
ALF Briso $\bullet$ V Rahal $\bullet$ RH Sundfeld \\ $\mathrm{PH}$ dos Santos $\bullet$ RS Alexandre
}

\begin{abstract}
Clinical Relevance
Bleaching with either $10 \%$ carbamide peroxide or $35 \%$ hydrogen peroxide impairs the formation of the hybrid layer, resin tags, and bond strength. The use of sodium ascorbate following bleaching diminishes this adverse effect in the case of $10 \%$ carbamide peroxide but not so when $35 \%$ hydrogen peroxide is used as the bleaching agent.
\end{abstract}

\section{SUMMARY}

The purpose of this study was to analyze the influence of $10 \%$ sodium ascorbate (SA) on the hybrid layer, resin tag length, and bond strength to dentin after bleaching. Six groups were tested: G C, control; G SA, sodium ascor-

*André LF Briso, DDS, MS, PhD, associate professor, Araçatuba Dental School, UNESP-Univ Estadual Paulista, Restorative Dentistry, Araçatuba, Brazil

Vanessa Rahal, DDS, MS, PhDc, Araçatuba Dental School, UNESP-Univ Estadual Paulista, Restorative Dentistry, Araçatuba, Brazil

Renato Herman Sundfeld, DDS, MS, PhD, associate professor, Araçatuba Dental School, UNESP-Univ Estadual Paulista, Restorative Dentistry, Araçatuba, Brazil

Paulo Henrique dos Santos, DDS, MS, PhD, associate professor, Araçatuba Dental School, UNESP-Univ Estadual Paulista, Dental Materials and Prosthodontics, Araçatuba, Brazil

Rodrigo Sversut Alexandre, DDS, MS, PhD, research collaborator, Araçatuba Dental School, UNESP-Univ Estadual Paulista, Restorative Dentistry, Araçatuba, Brazil

*Corresponding author: R José Bonifácio, 1193, Araçatuba, São Paulo 16015-050, Brazil; e-mail: alfbriso@foa.unesp.br DOI: $10.2341 / 12-054-\mathrm{L}$ bate (SA) + restoration; G CP, bleaching with carbamide peroxide $(\mathrm{CP})+$ restoration; $G$ CP+SA, bleaching with $\mathrm{CP}+\mathrm{SA}+$ restoration; G HP, bleaching with $35 \%$ hydrogen peroxide (HP) + restoration; and G HP+SA, HP + SA + restoration. After dental bleaching, the dentin was exposed and the antioxidant solution was applied to groups G SA, G CP+SA, and G HP+SA, before bonding procedures. The teeth were sectioned in the mesiodistal direction. One section was decalcified, and the specimens were embedded in paraffin and sectioned in the longitudinal direction with a thickness of 6 $\mu \mathrm{m}$. Fifteen slices of each specimen were selected according to a systematic sample of slices with an interval proportional to the total number of slices obtained for each tooth. The specimens were stained using the Brown \& Brenn method, and an optic microscope was used to analyze the hybrid layer thickness and resin tag length. The remaining tooth segment was sectioned into stick-shaped specimens and used for microtensile bond strength testing $(0.5 \mathrm{~mm} / \mathrm{min})$. Statistical analysis was performed using two-way analysis of variance and Fisher test. The results for hybrid layer + 
tag formation (in micrometers) were $\mathrm{G} C, \mathbf{1 3 . 2 7}$ Aa; G SA, 11.85 Ba; G CP, 6.84 Bb; G CP+SA, 9.02 $\mathrm{Ab}$; G HP, 7.28 Bb; and G HP+SA, 9.22 Ab; bond strength results (in MPa) were $\mathrm{G}$ C, $49.5 \mathrm{Aa}$; $\mathrm{G}$ SA, 51.7 Aa; G CP, 37.16 Bb; G CP+SA, 47.69 Aa; G HP, 32.39 Ab; and G HP+SA, 39.67 Ab. Tooth bleaching with CP or HP impairs the formation of the hybrid layer and resin tags and reduces the microtensile bond strength. Statistically, the use of SA significantly increases the hybrid layer thickness and resin tag length. The microtensile bond strength values for carbamide peroxide increased, but the microtensile bond strength for hydrogen peroxide was not affected.

\section{INTRODUCTION}

In general, the techniques for tooth bleaching are simple and generate positive esthetic results when the manufacturer's directions are followed. In addition to the traditional at-home bleaching technique with carbamide peroxide products in bleaching trays, hydrogen peroxide at high concentration has produced faster results for those patients who cannot or do not want to wear the trays. ${ }^{1,2}$

It is suggested that esthetic restorations should be replaced after tooth bleaching, since color alteration affects tooth structure but not restorative materials. ${ }^{3,4}$ A 7-day waiting period following bleaching is recommended before replacing adhesive restorations because bleaching products adversely affect the bonding of resin materials to the tooth and overcome low bond strength values to bleached dental surfaces, which may negatively influence the clinical performance of restorations. ${ }^{2,4-7}$ Moreover, there are other reasons for delaying restorative procedures, such as reducing postoperative sensitivity and to allow time for color rebound, which may alter esthetic results. ${ }^{8-10}$

It is worth noting that most of the bonding studies have been conducted with resins placed primarily in enamel, ${ }^{1,7,11,12}$ while some recent studies evaluated the effect of tooth bleaching on bonding to dentin. ${ }^{2,13-17}$ Most restorative procedures use enamel and dentin as substrates for adhesion.

In the traditional adhesive technique with prior acid etching, the smear layer and smear plug are removed and superficial demineralization of dentin occurs, exposing the collagen fibers. The penetration of the adhesive system into this demineralized structure and in the tubules allows formation of a hybridized region (resin tags + hybrid layer), which restores the structural resistance of the etched region ${ }^{18}$ and prevents the occurrence of microleakage. $^{19}$

Although some authors have indicated that a thin hybrid layer can have a performance similar to a thicker one ${ }^{20}$ other studies ${ }^{21,22}$ have reported that a thin hybrid layer and a reduced penetration of the adhesive systems in dentin could result in lower bond strength values.

Many studies consider a $10 \%$ sodium ascorbate (SA) solution to be an effective choice to improve dentin bonding and defend the use of SA as the most efficient agent for neutralizing the oxidizing effects of bleaching agents. Its use may also increase the strength of the dentin bond. ${ }^{11,13,14,23-25}$ The antioxidant type, concentration, form, and duration of application have been considered important factors for improving bonding after bleaching treatment. ${ }^{15-17,24,25}$

The reducing capacity or ability to neutralize and reverse the oxidizing effects of hydrogen peroxide in biological systems has already been reported. ${ }^{26,27}$ Some authors have suggested that the use of SA after bleaching can reverse the reduced adhesion between adhesive materials and dental tissue. ${ }^{11,13,17,24,25}$

However, since there are no significant reports emphasizing the effect of antioxidant agents on the formation of the hybrid layer and resin tags, laboratory studies are necessary to assess the effect of bleaching agents and antioxidants on the micromechanical interaction occurring in dentin. The purpose of this current study was to evaluate the influence of $10 \%$ SA solution following two bleaching techniques on the bond strength in dentin. The microtensile test was used for evaluation.

The null hypothesis tested was that the use of SA does not influence the hybridization depth or the microtensile bond strength in dentin after bleaching.

\section{MATERIALS AND METHODS}

This study investigated the influence of $10 \%$ SA on the hybrid layer, resin tag length, and bond strength to dentin after dental bleaching with two different materials (Table 1 ).

Thirty-six human premolars without any cracks and that were extracted for other purposes were divided into six experimental groups $(n=6)$ according to the bleaching procedures and the use of antioxidant. The teeth were cleaned with manual periodontal curettes (Duflex Ltda, Rio de Janeiro, Rio de 


\begin{tabular}{|c|c|c|c|c|c|}
\hline & Material & Composition & Manufacturer & Lot & Mode of Application \\
\hline Composite resin & Z-250 & $\begin{array}{l}\text { UDMA: urethane } \\
\text { dimethacrylate; Bis-EMA: } \\
\text { bisphenol A polyethylene } \\
\text { glycol diether dimethacrulate; } \\
\text { TEGDMA: tri-ethylene glycol } \\
\text { dimethacrylate; inorganic } \\
\text { particles }\end{array}$ & $\begin{array}{l}\text { 3M/ESPE, St Paul, } \\
\text { MN, USA }\end{array}$ & $6 \mathrm{CR}$ & $\begin{array}{l}\text { Two } 2.0-\mathrm{mm} \text {-thick flat } \\
\text { composite resin } \\
\text { increments }\end{array}$ \\
\hline Adhesive system & $\begin{array}{l}\text { Adper Scotchbond } \\
\text { Multi Purpose }\end{array}$ & $\begin{array}{l}\text { Primer: HEMA, polyalkenoic } \\
\text { acid copolymer; adhesive: } \\
\text { Bis-GMA, HEMA, } \\
\text { photoinitiators }\end{array}$ & $\begin{array}{l}\text { 3M/ESPE, St Paul, } \\
\text { MN, USA }\end{array}$ & $\begin{array}{l}\text { Primer: } 6 \mathrm{BC}, \\
\text { adhesive: } 6 \mathrm{PL}\end{array}$ & $\begin{array}{l}\text { According to } \\
\text { manufacturer's } \\
\text { instructions }\end{array}$ \\
\hline Bleaching products & $\begin{array}{l}\text { Whiteness HP } \\
\text { Maxx }\end{array}$ & $\begin{array}{l}35 \% \text { Hydrogen peroxide, } \\
\text { thickening stain's mixture, } \\
\text { glycol, and deionized water }\end{array}$ & $\begin{array}{l}\text { FGM - Dental } \\
\text { Products, Joinvile, } \\
\text { Brazil }\end{array}$ & 270206 & $\begin{array}{l}\text { Four sessions, one } \\
\text { session per week, } \\
\text { three } 15 \text {-minute } \\
\text { applications per } \\
\text { session }\end{array}$ \\
\hline Antioxidant & $\begin{array}{l}10 \% \text { Sodium } \\
\text { ascorbate }\end{array}$ & $\begin{array}{l}10 \% \text { Sodium ascorbate and } \\
\text { osmolality water }\end{array}$ & $\begin{array}{l}\text { Farmácia } \\
\text { Aphoticário, } \\
\text { Araçatuba, Brazil }\end{array}$ & No batch number & $\begin{array}{l}\text { 10-minute application } \\
\text { before bonding } \\
\text { procedures }\end{array}$ \\
\hline
\end{tabular}

Janeiro, Brazil) using distilled water to remove periodontal tissues, washed using pumice and water in a rubber cup, coupled to a slow-speed hand piece (Dabi Atlante, Ribeirão Preto, SP, Brazil), and rinsed and stored in $0.1 \%$ neutral thymol solution at room temperature until the beginning of the research.

The current study design was analyzed and approved by the Institutional Review Board for Investigations (2009-2384). Throughout the study, specimens from all study groups were stored in artificial saliva at $37^{\circ} \mathrm{C}$.

In groups carbamide peroxide $(\mathrm{CP})$ and $\mathrm{CP}+\mathrm{SA}$, a commercial $10 \% \mathrm{CP}$ at-home bleaching gel (Whiteness Standard, FGM Produtos Odontológicos Ltda, Joinville, SC, Brazil) was applied to the buccal and occlusal surfaces (0.06 mL per tooth) using a graduated 1-mL syringe for four hours per day, according to the manufacturer's instructions. The specimens were thoroughly rinsed with air-water spray and stored in artificial saliva $(\mathrm{pH}=6.7)$.

The specimens from groups hydrogen peroxide (HP) and $\mathrm{HP}+\mathrm{SA}$ were bleached using $35 \%$ hydrogen peroxide (Whiteness HP Maxx, FGM Produtos Odontológicos Ltda) applied to the buccal and occlusal surface in a layer of about $1.0 \mathrm{~mm}$ in thickness $(0.06 \mathrm{~mL})$. After one minute, the product was exposed to a quartz-tungsten-halogen light (Ultralux, Dabi Atlante) with a light output of 450 $\mathrm{mW} / \mathrm{cm}^{2}$ for 20 seconds, according to the manufacturer's instruction. The product remained on the dental surface for 15 minutes with no light source. Four bleaching sessions were performed, and three applications of the bleaching product were made during each session. After each bleaching sessions, the specimens were stored in artificial saliva until the next session (seven days later).

After performing the bleaching procedures, the occlusal surfaces of all specimens were abraded with 600-grit abrasive paper disks (Carbimet Paper Disks, Buehler, Lake Bluff, IL, USA) in the polisher Aropol E (Arotec Industria e Comércio Ltda) at a constant speed and under irrigation until dentin exposure. The specimens from groups $\mathrm{CP}+\mathrm{SA}$ and $\mathrm{HP}+\mathrm{SA}$, bleached with $10 \% \mathrm{CP}$ and $35 \% \mathrm{HP}$, respectively, had the SA antioxidant solution (Farmácia Aphoticário, Araçatuba, SP, Brazil) applied on the dentin surface for 10 minutes at $1 \mathrm{~mL} / \mathrm{min}$. The specimens were then rinsed with distilled water for 30 seconds, and bonding procedures were performed immediately after SA application. For that purpose, the exposed dentin substrate was rinsed, dried, and etched with $35 \%$ phosphoric acid gel (Scotchbond Etchant, 3M ESPE, St Paul, MN, USA) for 15 


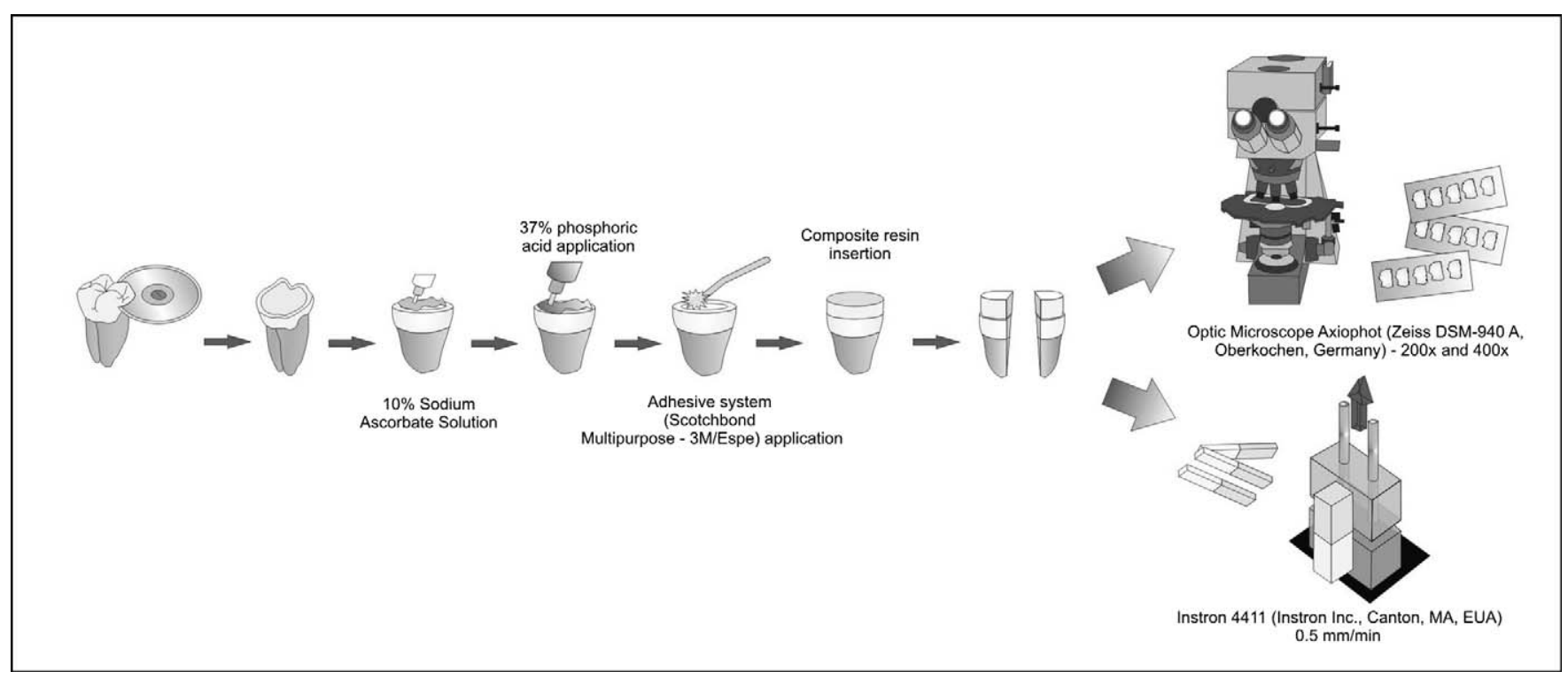

Figure 1. Methodology scheme of the teeth sectioning into two equal parts used for microtensile test and hybrid layer and tag formation analysis.

seconds. Then, the substrate was rinsed again for 10 seconds and dried with compressed air spray with the dentin protected by a small cotton ball to maintain the humidity of the tissue. A layer of the two-step adhesive system primer (Adper Scotchbond Multi-Purpose, 3M/ESPE) was applied on the dentin followed by the application of a layer of the hydrophobic component. Light polymerization was carried out with a halogen light-curing unit for 10 seconds at a light output of $450 \mathrm{~mW} / \mathrm{cm}^{2}$. The composite resin (Filtek Z250, 3M ESPE), shade A2, was inserted using a Thompson spatula and light polymerized for 40 seconds.

In group SA, 10\% SA antioxidant solution (Table 1) was applied as described for groups $\mathrm{CP}+\mathrm{SA}$ and $\mathrm{HP}+\mathrm{SA}$, after dentin exposure. Afterward, bonding procedures were performed.

Group C was the control, and bonding procedures were performed after dentin exposure with no previous treatments.

After the restorative procedures, all of the specimens were sectioned into two equal parts, in the mesiodistal direction, using the metallographic cutter ISOMET 2000 (Buehler) under water cooling and at a speed of $800 \mathrm{rpm}$ and static load of $160 \mathrm{~g}$ (Figure 1). One section was decalcified over three months in a solution containing 50\% formic acid and 20\% sodium citrate. After demineralization, the specimens were immersed in alcohol solutions at different concentrations for dehydration. Immediately after this procedure, the specimens were immersed in xylol for one hour. The restorations were carefully removed, and the specimens were embedded in paraffin and sectioned in the longitudinal direction with a slice thickness of $6 \mu \mathrm{m}$. Fifteen slices of each specimen were selected according to a systematic sample of slices with an interval proportional to the total number of slices obtained for each tooth.

The selected slides were stained using the Brown \& Brenn method and analyzed with an optical light microscope (Axiophot, Carl Zeiss Company, Oberkochen, Germany). The hybrid layer thickness and resin tag length were analyzed with the micrometric ocular piece 40/075.

Each slice generated three images at $400 \times$ of the mesial, middle, and distal thirds. In each visual field, the hybrid layer + resin tags were measured at five different areas using the Axiovision Software Rel. 4.6 (Carl Zeiss Company), as demonstrated in Figure 2.

The other tooth section was used for microtensile bond strength testing. A metallographic cutter was used under water cooling at a speed of $800 \mathrm{rpm}$ and static load of $160 \mathrm{~g}$ to obtain stick-shaped specimens from the central region of each tooth, totaling 30 specimens per group.

These specimens were fixed to the Universal Test Machine Instron Model 4411 (Instron Inc, Canton, MA, USA), using cyanoacrylate adhesive (Super Bonder, Henkel Ltda, Itapevi, São Paulo, Brazil) and tested with a $50 \mathrm{~N}$ load cell at a speed of $0.5 \mathrm{~mm} /$ min until failure. The bond strength values of the sticks from the same tooth were averaged, and only the bond strength values of the six teeth from each 


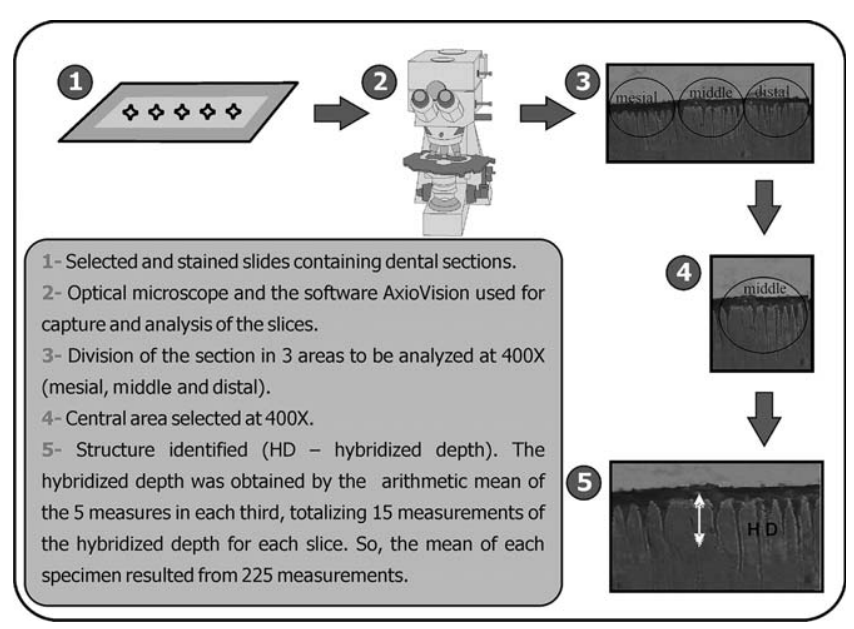

Figure 2. Methodological sequence used to obtain the hybrid layer thickness and resin tags length.

experimental condition were analyzed statistically. Premature failures were not considered in the data analysis.

The results obtained for hybrid layer + resin tags and microtensile bond strength were submitted to two-way analysis of variance (ANOVA) and Fisher PLSD test, at a level of significance of $5 \%$, to verify the effect of the treatments on dentin bonding.

The fracture pattern was analyzed in the stereoscopic Stemi SV 11 (DSM-940 A, Carl Zeiss Company) at $30 \times$ magnification. To reveal the fracture area of each specimen more clearly, the revealing solution proposed by Ohkubo and others in $1982^{28}$ was applied on the fractured region, which stained the resin-free dental structure. Images were analyzed using Image $\mathrm{J}$ Software (Image Processing and Analysis in Java, NIH, Bethesda, MD, USA), and the fracture patterns were determined.

\section{RESULTS}

Means of hybrid layer + resin tags $(\mu \mathrm{m})$ and microtensile bond strength are summarized in Tables 2 and 3. ANOVA showed that significant differences were observed among the groups for both analyzed factors $(p<0.05$; Tables 4 and 5$)$.
Specimens from G C showed greater resin tag length and hybrid layer thickness, suggesting a continuous and frequent micromechanical interaction (Figure 3). When SA was used before the restoration procedures and without bleaching treatment (group SA), the hybrid layer + resin tags were thinner than the control group $(p=0.0038)$. The bleached specimens from groups CP and HP showed the lowest adhesive penetration means, presenting unusual, fewer, and shorter resin tags and a thinner hybrid layer; no significant difference was found between these groups ( $p=0.335)$. It was also verified that SA resulted in an increase in resin tag length and hybrid layer thickness for both $\mathrm{CP}+\mathrm{SA}$ (Figure 4) and $\mathrm{HP}+\mathrm{SA}$ (Figure 5).

For the microtensile bond strengths, group $\mathrm{C}$ and group SA showed statistically similar values $(p=0.59)$. In the $\mathrm{CP}$ group, the $\mathrm{SA}$ application increased the values of microtensile bond strength, but the SA application was not effective for the $35 \%$ HP bleached teeth (Tables 3 and 5).

Fracture pattern analysis showed a prevalence of adhesive failures. Groups $\mathrm{CP}$ and $\mathrm{HP}+\mathrm{SA}$ presented a high incidence of cohesive failures in dentin, while cohesive failures in resin were frequent in groups $\mathrm{C}$ and SA (Figure 6).

\section{DISCUSSION}

At-home bleaching techniques have been widely used to obtain improved esthetic results. ${ }^{3}$ Many studies have been conducted to clarify the interaction of bleaching, its effect on hard tissues, and its influence on bonding adhesive restorative materials to the tooth structure. ${ }^{12}$

In recent studies, microleakage, a decrease in bonding strength, and low micromechanical interaction were associated with bleaching procedures. ${ }^{6,29,30}$ These conditions were augmented when the in-office bleaching technique, which uses bleach at a higher concentration, was performed. ${ }^{31,32}$ As a result, a 24-hour to one-month waiting period after bleaching has been recommended before performing restorative procedures. ${ }^{2,6,29}$

\begin{tabular}{|c|c|c|c|}
\hline & Group C & Group CP & Group HP \\
\hline No SA & $13.27 \pm 0.94 \mathrm{~A} \mathrm{a}$ & $6.84 \pm 0.41 \mathrm{~B} \mathrm{~b}$ & $7.28 \pm 0.36 \mathrm{~B} \mathrm{~b}$ \\
\hline
\end{tabular}




\begin{tabular}{|c|c|c|c|}
\hline & Group C & Group CP & Group HP \\
\hline No SA & $49.54 \pm 8.09 \mathrm{~A} \mathrm{a}$ & $37.16 \pm 3.10 \mathrm{~B} \mathrm{~b}$ & $32.39 \pm 11.73 \mathrm{~A} \mathrm{~b}$ \\
\hline
\end{tabular}

\begin{tabular}{|lccrrrrr|}
\hline Table 4 & Analysis of Variance Table for Hybrid Layer + Resin Tags & & \\
\hline & $\boldsymbol{d f}$ & Sum of Squares & Mean Square & F-Value & $\boldsymbol{p}$-Value & Lambda & Power \\
\hline Bleaching agent & 2 & 160.661 & 80.330 & 131.124 & $<0.0001$ & 262.248 & 1.000 \\
\hline Antioxidant agent & 1 & 7.326 & 7.326 & 11.958 & 0.0017 & 11.958 & 0.934 \\
\hline Bleaching agent/antioxidant agent & 2 & 24.255 & 12.128 & 19.796 & $<0.0001$ & 39.592 & 1.000 \\
\hline Residual & 30 & 18.379 & .613 & & &
\end{tabular}

The decrease in bond strength and reduction of the adhesive system interaction in bleached teeth are attributed to the presence of residual oxygen. ${ }^{13,17,33,34}$ This highly reactive chemical element eliminates pigmentation but also reacts with the free radicals of the resin materials, which inhibits polymerization and generates polymers with reduced mechanical properties. ${ }^{25,33,35,36}$ Some studies in dental enamel suggest that the amount of residual oxygen is proportional to the reduction in bonding and the reduced length and frequency of resin tags in the bleached substrate. ${ }^{6,29}$ Data found in the current study also showed a reduced hybrid layer and resin tag formation. This result may be related to mechanical modifications in peritubular and intertubular dentin produced by bleaching agents that could lead to biomechanical alterations, but there is no evidence to substantiate this. ${ }^{30,37}$

Histochemical studies have shown reduced levels of sulfur in samples bleached with HP or CP. Sulfur is a component of proteoglycans (chondroitin sulfate and keratan sulfate), and changes in their levels indicate damage to the organic dentin matrix. ${ }^{38-40}$

These changes in proteoglycans might interfere in the maintenance of interfibrillar spaces, ${ }^{41}$ which may have compromised diffusion of the adhesive into the collagen network, potentially reducing the bond strength in this current study. ${ }^{42,43}$
The specimens from group C (Figure 3) presented a thick hybrid layer + resin tags and also high microtensile bond strength values. The bleached groups (G $\mathrm{CP}$ and G HP), which presented similar results to those from previous studies, demonstrated the deleterious effects of the oxygen released by the bleaching agents. ${ }^{5,13,29,35}$

For those groups that received the solution of $10 \%$ SA, the group SA exhibited a reduced hybrid layer thickness + resin tag length $(11.85 \mu \mathrm{m})$ and was considered as a control group. Although many studies report the advantages of using this antioxidant substance with bleached teeth, ${ }^{11,13,24}$ few studies considered the use of ascorbate with unbleached teeth. ${ }^{13,44}$ In the current study, the use of SA alone led to limited resin tags and hybrid layer when compared with the control group, although their formations remained continuous and homogeneous across the adhesive interface. Although the hybrid layer + resin tag thickness decreased in the SA group when compared with the control group, the microtensile bond strength values were similar. This difference might not be clinically significant, since the bond strength was satisfactory for both groups.

The use of SA immediately after bleaching (groups $\mathrm{CP}+\mathrm{SA}$ and $\mathrm{HP}+\mathrm{SA}$ ) increased the hybrid layer and resin tag length when compared with groups $\mathrm{CP}$ and HP (Figures 4 and 5), but the effect was not as great

Table 5 Analysis of Variance Table for Bond Strength

\begin{tabular}{|lrcrrrrr|}
\hline & $d \boldsymbol{d}$ & Sum of Squares & Mean Square & $\boldsymbol{F}$-Value & $\boldsymbol{p}$-Value & Lambda & Power \\
\hline Bleaching agent & 2 & 1287.886 & 643.943 & 11.423 & 0.0002 & 22.846 & 0.993 \\
\hline Antioxidant agent & 1 & 400.067 & 400.067 & 7.097 & 0.0123 & 7.097 & 0.738 \\
\hline Bleaching agent/antioxidant agent & 2 & 105.963 & 52.982 & .940 & 0.4019 & 1.880 & 0.191 \\
\hline Residual & 30 & 1691.203 & 56.373 & & & \\
\hline
\end{tabular}




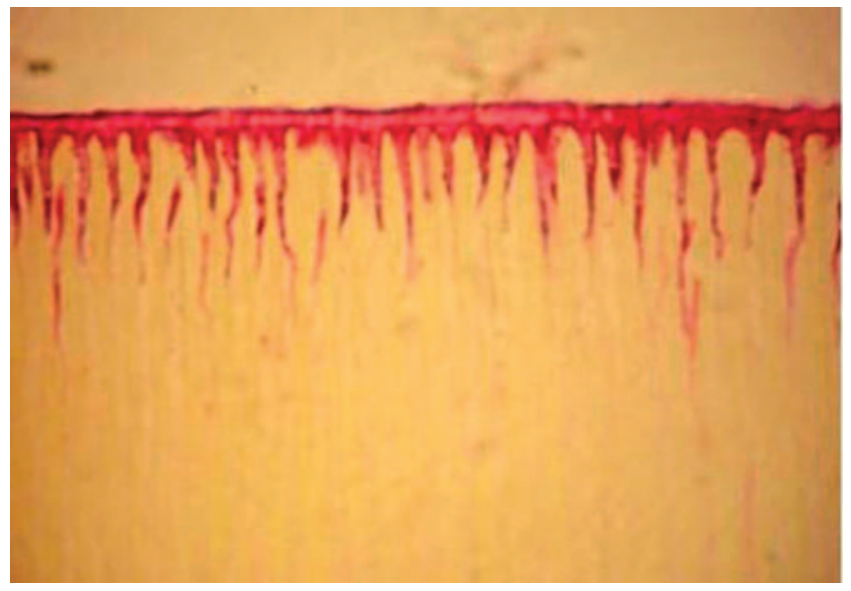

Figure 3. Photomicrograph (group C) showing a continuous hybrid layer and frequent resin tags formation analyzed by common optical microscopy (400x magnification).

as that from group C. Nevertheless, the hybrid layer and resin tag formation were homogeneous and continuous, especially for group $\mathrm{CP}+\mathrm{SA} \cdot{ }^{13,25,30}$ Moreover, although some authors ${ }^{20}$ reported that hybrid layer depth is not usually related to bond strength, higher bond strength values were also verified in this experimental group.

However, in the hydrogen peroxide group $(\mathrm{HP}+\mathrm{SA})$, the bond strength values were not improved when the bleaching agent was followed by an application of SA. This may be explained by the use of highly concentrated products ${ }^{45}$ and suggests that the use of SA was not sufficient to improve the resin tag and hybrid layer formation. It has been demonstrated that, as the duration of application for the antioxidant increases, the bond strength of the composite to dentin tissue also increases. ${ }^{24}$

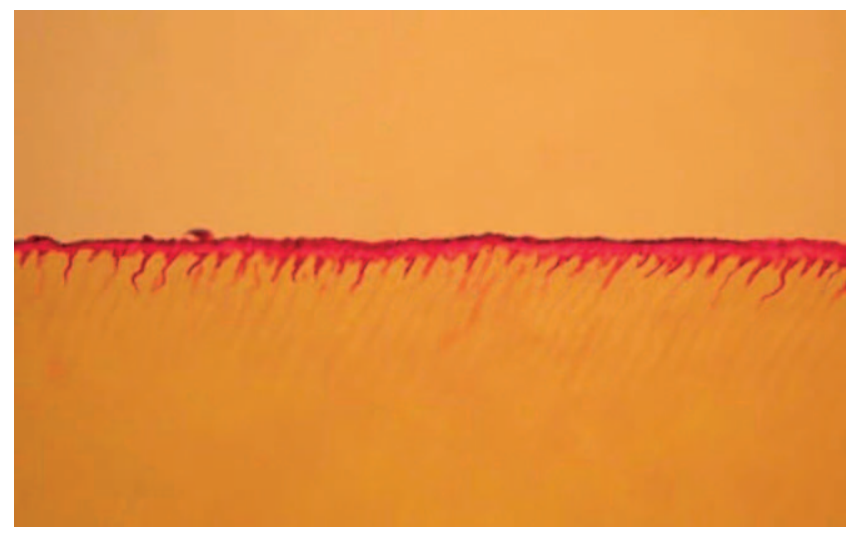

Figure 4. Photomicrograph (group $C P+S A$ ) analyzed by common optical microscopy (400x magnification), showing a thick continuous hybrid layer and frequent but short resin tags formation.

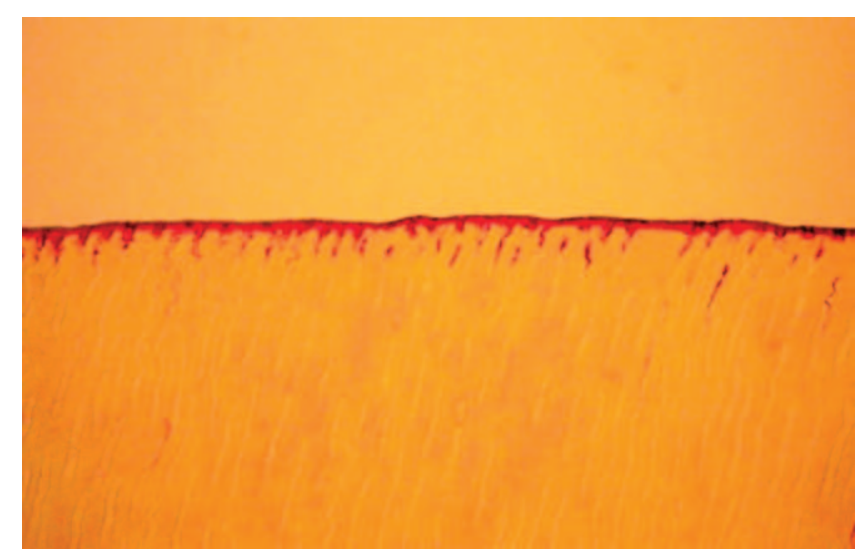

Figure 5. Photomicrograph (group HP+SA) analyzed by common optical microscopy (400x magnification), showing a thin and continuous hybrid layer but sparse and short resin tags formation.

According to the results of the present study, the use of SA improved adhesion in bleached teeth, suggesting that the antioxidant action may reverse (partially or fully) the damaging effects of the bleaching products. ${ }^{11,13,17,24,25}$ It is possible that by restoring the reducing potential (redox) of the oxidized substrate, SA limits premature polymerization of the free radicals of the adhesive and therefore cancels (reverses) the effects of the impaired bonding on the bleached dentin. ${ }^{13,34}$

Additional studies are required to further explain the mechanism of this reversal process, its role on bonding, and the possible beneficial effects of its systemic application. It is important to suggest additional studies comparing the effect of different antioxidant solutions considering the instability of these compounds, ${ }^{46}$ which limit their use to only a few hours after manipulation. The clinical implica-

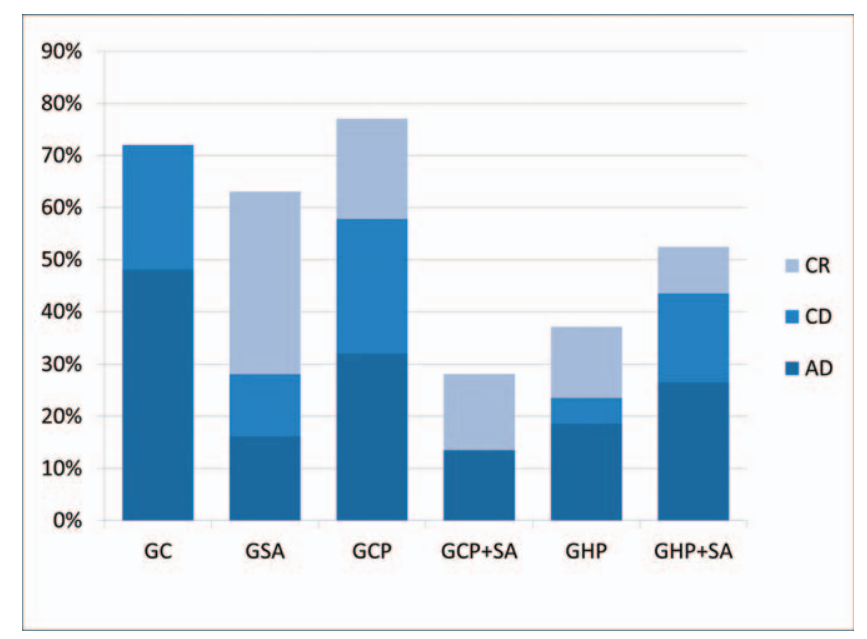

Figure 6. Fracture pattern for the study groups. Cohesive in resin $(C R)$; cohesive in dentin (CD); adhesive (AD). 
tion of this present study is that the application of an antioxidant can shorten the time period spent in the clinic by both dentists and patients to allow restorative procedures to be performed after bleaching treatments. ${ }^{16}$

Therefore, the current results do not support full acceptance of the null hypothesis, that the use of SA does not influence the hybrid layer and resin tag formation and the microtensile bond strength in dentin after bleaching.

\section{CONCLUSIONS}

Based on the present results, dental bleaching using $10 \% \mathrm{CP}$ or $35 \% \mathrm{HP}$ is damaging to resin tag and hybrid layer formation. When SA was applied following bleaching with $\mathrm{CP}$, a better hybrid layer thickness and resin tag length developed. In this case, there was an improvement in the microtensile bond strength values. This was not the case when SA was applied following bleaching with $35 \% \mathrm{HP}$.

\section{Acknowledgements}

This investigation was supported by FAPESP (06/55571-9).

\section{Conflict of Interest}

The authors have no proprietary, financial, or other personal interest of any nature or kind in any product, service, and/or company that is presented in this article.

\section{(Accepted 20 March 2013)}

\section{REFERENCES}

1. Bistey T, Nagy IP, Simó A, \& Hegedus C (2007) In vitro FT-IR study of the effects of hydrogen peroxide on superficial tooth enamel Journal of Dentistry 35(4) 325-330.

2. Spyrides GM, Perdigão J, Pagani C, Araújo MA, \& Spyrides SM (2000) Effect of whitening agents on dentin bonding Journal of Esthetic Dentistry 12(5) 264-270.

3. Haywood VB, \& Heymann HO (1989) Nightguard vital bleaching Quintessence International 20(3) 173-176.

4. Garcia EJ, Mena-Serrano A, de Andrade AM, Reis A, Grande RHM, \& Loguercio AD (2012) Immediate bonding to bleached enamel treated with $10 \%$ sodium ascorbate gel: a case report with one-year follow-up European Journal of Esthetic Dentistry 7(2) 154-162.

5. Comlekoglu ME, Gokce B, Kaya AD, Turkun M, \& Ozpinar B (2010) Reversal of reduced bond strength after bleaching General Dentistry 58(3) 258-263.

6. Sundfeld RH, Briso AL, De Sá PM, Sundfeld ML, \& Bedran-Russo AK (2005) Effect of time interval between bleaching and bonding on tag formation Bulletin of Tokyo Dental College 46(1-2) 1-6.

7. Uysal T, Basciftci FA, Uşümez S, Sari Z, \& Buyukerkmen A (2003) Can previously bleached teeth be bonded safely?
American Journal of Orthodontics and Dentofacial Orthopedics 123(6) 628-632.

8. Matis BA, Mousa HN, Cochran MA, \& Eckert GJ (2000) Clinical evaluation of bleaching agents of different concentrations Quintessence International 31(5) 303-310.

9. Khoroushi M, Mazaheri H, \& Manoochehri A (2011) Effect of CPP-ACP application on flexural strength of bleached enamel and dentin complex Operative Dentistry 36(4) $372-379$.

10. Alomari Q, \& El Daraa E. (2010) A randomized clinical trial of in-office dental bleaching with or without light activation Journal of Contemporary Dental Practice 11(1) E017-E024.

11. Bulut H, Türkün M, \& Kaya AD (2006) Effect of an antioxidizing agent on the shear bond strength of brackets bonded to bleached human enamel American Journal of Orthodontics and Dentofacial Orthopedics 129(2) 266-272.

12. Moule CA, Angelis F, Kim GH, Le S, Malipatil S, Foo MS, Burrow MF, \& Thomas D (2007) Resin bonding using an all-etch or self-etch adhesive to enamel after carbamide peroxide and/or CPP-ACP treatment. Australian Dental Journal 52(2) 133-137.

13. Lai SC, Mak YF, Cheung GS, Osorio R, Toledano M, Carvalho RM, Tay FR, \& Pashley DH (2001) Reversal of compromised bonding to oxidized etched dentin Journal of Dental Research 80(10) 1919-1924.

14. Türkün M, Çelik EU, Kaya AD, \& Arici M (2009) Can the hydrogel form of sodium ascorbate be used to reverse compromised bond strength after bleaching? Journal of Adhesive Dentistry 11(1) 35-40.

15. Lima AF, Fonseca FMS, Freitas MS, Palialol ARM, Aguiar FHB, \& Marchi GM (2011) Effect of bleaching treatment and reduced application time of an antioxidant on bond strength to bleached enamel and subjacent dentin Journal of Adhesive Dentistry 13(6) 537-542.

16. Prasansuttiporn T, Nakajima M, Kunawarote S, Foxton RM, \& Tagami J (2011) Effect of reducing agents on bond strength to NaOCL-treated dentin Dental Materials 27(3) 229-234.

17. Sasaki RT, Flório FM, \& Basting RT (2009) Effect of $10 \%$ sodium ascorbate and $10 \%$ alpha-tocopherol in different formulations on the shear bond strength of enamel and dentin submitted to a home-use bleaching treatment Operative Dentistry 34(6) 746-752.

18. Perdigão J, Frankenberger R, Rosa BT, \& Breschi L (2000) New trends in dentin/enamel adhesion American Journal of Dentistry 13(Spec No) 25D-30D.

19. Fusayama $\mathrm{T}$ Posterior adhesive composite resin: a historic review (1990) Journal of Prosthetic Dentistry 64(5) 534-538.

20. Perdigão J, May KN Jr, Wilder AD Jr, \& Lopes M (2000) The effect of depth of dentin demineralization on bond strengths and morphology of the hybrid layer Operative Dentistry 25(3) 186-194.

21. Hosaka K, Nakajima M, Monticelli F, Carrilho M, Yamauti M, Aksornmuang J, Nishitani Y, Tay FR, Pashley DH, \& Tagami J (2007) Influence of hydrostatic 
pulpal pressure on the microtensile bond strength of allin-one self-etching adhesives Journal of Adhesive Dentistry 9(5) 437-442.

22. Vachiramon V, Vargas MA, Pashley DH, Tay FR, Geraldeli S, Qian F, \& Armstrong SR (2008) Effects of oxalate on dentin bond after 3-month simulated pulpal pressure Journal of Dentistry 36(3) 178-185.

23. Buettner GR (1993) The pecking order of free radicals and antioxidants: lipid peroxidation, alpha-tocopherol, and ascorbate Archives of Biochemistry and Biophysics $\mathbf{3 0 0 ( 2 )}$ 535-543.

24. Kaya $\mathrm{AD}$, \& Türkün $\mathrm{M}$ (2003) Reversal of dentin bonding to bleached teeth Operative Dentistry 28(6) 825-829.

25. Kimyai S, \& Valizadeh H (2008) Comparison of the effect of hydrogel and a solution of sodium ascorbate on dentincomposite bond strength after bleaching Journal of Contemporary Dental Practice 9(2) 105-112.

26. Carr AC, Tijerina T, \& Frei B (2000) Vitamin C protects against and reverses specific hypochlorous acid- and chloramine-dependent modifications of low-density lipoprotein Biochemical Journal 346(2) 491-499.

27. Smit MJ, \& Anderson R (1992) Biochemical mechanisms of hydrogen peroxide and hypochlorous acid-mediated inhibition of human mononuclear leukocyte functions in vitro: protection and reversal by anti-oxidants Agents and Actions 36(1-2) 58-65.

28. Ohkubo N, Iwata S, Chikada K, Kuriyama S, Narita M, Ishikawa T, \& Yoshida T (1982) A retention comparison of two sealants Bulletin of Tokyo Dental College 23(4) 201-219.

29. Da Silva Machado J, Cândido MS, Sundfeld RH, De Alexandre RS, Cardoso JD, \& Sundefeld ML (2007) The influence of time interval between bleaching and enamel bonding Journal of Esthetic and Restorative Dentistry 19(2) 111-118.

30. Forner L, Salmerón-Sánchez M, Palomares M, Llena C, \& Amengual J (2009) The use of atomic force microscopy in determining the stiffness and adhesion force of human dentin after exposure to bleaching agents Journal of Endodontics 35(10) 1384-1386.

31. Attin T, Paqué F, Ajam F, \& Lennon AM (2003) Review of the current status of tooth whitening with the walking bleach technique International Endodontic Journal 36(5) 313-329.

32. Tam LE, Kuo VY, \& Noroozi A (2007) Effect of prolonged direct and indirect peroxide bleaching on fracture toughness of human dentin Journal of Esthetic and Restorative Dentistry 19(2) 100-109.

33. Inai N, Kanemura N, Tagami J, Watanabe LG, Marshall SJ, \& Marshall GW (1998) Adhesion between collagen depleted dentin and dentin adhesives American Journal of Dentistry 11(3) 123-127.
34. Yiu CK, García-Godoy F, Tay FR, Pashley DH, Imazato S, King NM, \& Lai SC (2002) A nanoleakage perspective on bonding to oxidized dentin. Journal of Dental Research 81(9) 628-632.

35. Breschi L, Cadenaro M, Antoniolli F, Visintini E, Toledano M, \& Di Lenarda R (2007) Extent of polymerization of dental bonding systems on bleached enamel American Journal of Dentistry 20(4) 275-280.

36. Rueggeberg FA, \& Margeson DH (1990) The effect of oxygen inhibition on an unfilled/filled composite system Journal of Dental Research 69(10) 1652-1658.

37. Chng HK, Palamara JE, \& Messer HH (2002) Effect of hydrogen peroxide and sodium perborate on biomechanical properties of human dentin Journal of Endodontics 28(2) 62-67.

38. Bartold PM, Wiebkin OW, \& Thonard JC (1984) The effect of oxygen-derived free radicals on gingival proteoglycans and hyaluronic acid Journal of Periodontal Research 19(4) 390-400.

39. Moseley R, Waddington RJ, \& Embery G (1997) Degradation of glycosaminoglycans by reactive oxygen species derived from stimulated polymorphonuclear leukocytes Biochimica et Biophysica Acta 1362(2-3) 221-231.

40. Roberts CR, Mort JS, \& Roughley PJ (1987) Treatment of cartilage proteoglycan aggregate with hydrogen peroxide: relationship between observed degradation products and those that occur naturally during aging Biochemical Journal 247(2) 349-357.

41. Pereira PN, Bedran-de-Castro AK, Duarte WR, \& Yamauchi M (2007) Removal of noncollagenous components affects dentin bonding. Journal of Biomedical Materials Research Part B: Applied Biomaterials 80(1) 86-91.

42. Tay FR, Gwinnett AJ, \& Wei SH (1997) Ultrastructure of the resin-dentin interface following reversible and irreversible rewetting. American Journal of Dentistry 10(2) 77-82.

43. Carvalho RM, Mendonça JS, Santiago SL, Silveira RR, Garcia FC, Tay FR, \& Pashley DH (2003) Effects of HEMA/solvent combinations on bond strength to dentin Journal of Dental Research 82(8) 597-601.

44. Vongphan N, Senawongse P, Somsiri W, \& Harnirattisai C (2005) Effects of sodium ascorbate on microtensile bond strength of total-etching adhesive system to $\mathrm{NaOCl}$ treated dentine Journal of Dentistry 33(8) 689-695.

45. Camps J, Pommel L, Aubut V, \& About I (2010) Influence of acid etching on hydrogen peroxide diffusion through human dentin American Journal of Dentistry 23(3) 168-170.

46. Muraguchi K, Shigenobu S, Suzuki S, \& Tanaka T (2007) Improvement of bonding to bleached bovine tooth surfaces by ascorbic acid treatment Dental Materials Journal 26(6) $875-881$. 